Article

\title{
Active Infective Native and Prosthetic Valve Endocarditis: Short- and Long-Term Outcomes of Patients after Surgical Treatment
}

\author{
Mohamed Salem ${ }^{1, *}$, Christine Friedrich ${ }^{1}$, Mohammed Saad ${ }^{2}\left(\mathbb{D}\right.$, Derk Frank ${ }^{2}$, Mostafa Salem $^{2}$, \\ Thomas Puehler ${ }^{1}{ }^{1}$, Jan Schoettler ${ }^{1}$, Felix Schoeneich ${ }^{1}$, Jochen Cremer ${ }^{1}$ and Assad Haneya ${ }^{1}$ \\ 1 Department of Cardiovascular Surgery, Christian-Albrechts-University of Kiel, School of Medicine, \\ Arnold-Heller-Str. 3, D-24105 Kiel, Germany; Christine.Friedrich@uksh.de (C.F.); \\ thomas.puehler@uksh.de (T.P.); Jan.Schoettler@uksh.de (J.S.); Felix.schoeneich@uksh.de (F.S.); \\ Jochen.Cremer@uksh.de (J.C.); Assad.Haneya@uksh.de (A.H.) \\ 2 Department of Cardiology and Angiology, Christian-Albrechts-University of Kiel, School of Medicine, \\ Arnold-Heller-Str. 3, D-24105 Kiel, Germany; Mohammed.saad@uksh.de (M.S.); derk.frank@uksh.de (D.F.); \\ Mostafa.Salem@uksh.de (M.S.) \\ * Correspondence: Mohamed.Salem@uksh.de or drmohsalem83@hotmail.com; Tel.: +49-431500-67089
}

check for updates

Citation: Salem, M.; Friedrich, C.; Saad, M.; Frank, D.; Salem, M.; Puehler, T.; Schoettler, J.; Schoeneich, F.; Cremer, J.; Haneya, A. Active Infective Native and Prosthetic Valve Endocarditis: Short- and Long-Term Outcomes of Patients after Surgical Treatment. J. Clin. Med. 2021, 10, 1868. https://doi.org/10.3390/ jcm10091868

Academic Editors: Heinrich

Volker Groesdonk and

William Hurford

Received: 18 February 2021

Accepted: 21 April 2021

Published: 26 April 2021

Publisher's Note: MDPI stays neutral with regard to jurisdictional claims in published maps and institutional affiliations.

Copyright: (c) 2021 by the authors Licensee MDPI, Basel, Switzerland. This article is an open access article distributed under the terms and conditions of the Creative Commons Attribution (CC BY) license (https:// creativecommons.org/licenses/by/ $4.0 /)$.

\begin{abstract}
Background: Active infective endocarditis (IE) is a serious disease associated with high mortality. The current study represents our experience over 18 years with surgical treatment for active infective native and prosthetic valve endocarditis (INVE, IPVE). Method: Analysis of 413 patients (171 with IPVE vs. 242 with INVE) who underwent cardiac surgery due to IE between 2002 and 2020. Results: Patients with IPVE were significantly older ( $64.9 \pm 13.2$ years vs. $58.3 \pm 15.5$ years; $p<0.001)$ with higher EuroSCORE II $(21.2(12.7 ; 41.8)$ vs. $6.9(3.0 ; 17.0) ; p<0.001))$ and coronary heart disease $(50.6 \%$ vs. $38.0 \% ; p<0.011)$. Preoperative embolization was significantly higher within INVE (35.5\% vs. $16.4 \% ; p<0.001)$ with high incidence of cerebral embolization $(18.6 \%$ vs. $7.6 \% ; p=0.001)$ and underwent emergency curative surgery than the IPVE group $(19.6 \%$ vs. $10.6 \% ; p<0.001)$. However, patients with IPVE were significantly represented with intracardiac abscess $(44.4 \%$ vs.15.7\%; $p<0.001$ ). Intraoperatively, the duration of surgery was expectedly significantly higher in the IPVE group (356 min vs. $244 \mathrm{~min}$; $p=0.001$ ) as well as transfusion of blood (4 units (0-27) vs. 2 units $(0-14) ; p<0.001)$. Post-operatively, the incidence of bleeding was markedly higher within the IPVE group $(700 \mathrm{~mL}(438 ; 1163)$ vs. $500 \mathrm{~mL}(250 ; 1075) ; p=0.005)$. IPVE required significantly more permanent pacemakers $(17.6 \%$ vs. $7.5 \%: p=0.002)$. The 30 -day mortality was higher in the IPVE group $(24.6 \%$ vs. $13.2 \% ; p<0.003)$. Conclusion: Patients with INVE suffered from a higher incidence of cerebral embolization and neurological deficits than patients with IPVE. Surgical treatment in INVE is performed mostly as an emergency indication. However, patients with IPVE were represented commonly with intracardiac abscess, and had a higher indication of pacemaker implantation. The short- and long-term mortality rate among those patients was still high.
\end{abstract}

Keywords: infective native valve endocarditis; infective prosthetic valve endocarditis; intensive care therapy for infective endocarditis

\section{Introduction}

Active infective endocarditis (IE) is a serious disease. Despite improvement in its management, it is still associated with significant morbidity and mortality [1]. The risk factors are multifactorial. The most common causes are due to intravenous drug injections, prosthetic valve implantations and implantable pacemaker devices, patients with chronic indwelling catheters, and immunocompromised patients [2]. Surgical treatment of IE is required in $25-30 \%$ in acute cases and $20-40 \%$ in subacute and chronic cases [3]. Those surgical indications include recurrent embolism, the presence of prosthetic implantation, 
progressive heart failure, and the presence of resistant organisms [4,5]. While antibiotic therapy represents the first line in the treatment of IE, surgical treatment remains in many cases a lifesaving and emergency indication. The risk is increased in patients with infective prosthetic valve endocarditis (IPVE) compared to infective native valve endocarditis (INVE). Prior studies show diverging results regarding mortality after operations for IPVE [5-7]. This current study aimed to represent our experience over 18 years with surgical treatment in patients with IE and to compare short- and long-term survival after surgical therapy for INVE and IPVE.

\section{Materials and Methods}

\subsection{Patient Population}

The retrospective study included 413 consecutive patients who underwent open cardiac surgery due to IE between January 2002 and February 2020 in our tertiary university hospital. Patients underwent surgery either due to native or prosthetic valve IE exclusively; $171(41 \%)$ patients underwent surgery due to IPVE, while $242(59 \%)$ due to INVE. The primary endpoint was 30-day mortality. Secondary endpoints were long-term survival, intraoperative variables, and post-operative outcomes such as redo-surgery, blood loss, ventilation time, acute renal failure, and neurologic complications. Active IE was defined as patients receiving ongoing antibiotic therapy. The mortality included all causes leading to death during the hospital stay after the surgical treatment of IE within the post-operative 30 days. Data were supplied from the institution's database and medical records. Followup in terms of survival was determined by inquiries at the residents' registration offices. The study protocol was approved by the local Ethics Committee and informed consent was taken from the patients.

\subsection{Patient Management}

All cases of IE were discussed in our Endocarditis Team, consisting of a cardiologist, cardiac surgeon, and infectious disease consultant. The diagnosis was settled according to the modified Duke Criteria. Patients without microbiological prove of endocarditis was diagnosed according to another major and minor criterion of modified Duke criteria. A transthoracic echocardiogram was performed in all patients without exclusion. The measurements of interest included size and location of vegetation, presence of abscess or valve destruction, and left ventricle ejection fraction (LVEF). The antibiotics treatment starts as soon as IE was diagnosed and an intravenous treatment regime was introduced for at least 4-6 weeks independent of the time of surgery. Blood culture was taken in all patients to identify the organisms according to species and sensitivities. All patients referred with stroke underwent a computer tomography scan of the brain to exclude any risk of bleeding before surgery and to estimate the prognosis if patients have been intubated and in a coma. The neurological status of the patients was evaluated by a consultant neurologist. Perioperative characteristics and clinical variables, risk factors, intraoperative data, and predictors for mortality were analyzed.

\subsection{Surgical Procedure}

All patients underwent curative surgery performed by senior surgeons. The cardiopulmonary bypass $(\mathrm{CPB})$ was performed with direct cannulation of the ascending aorta. Venous drainage was performed either through direct cannulation of the right atrium in cases of aortic valve endocarditis or through double cannulation of superior and inferior vena cava in cases of mitral or tricuspid valve endocarditis followed by cross-clamping of ascending aorta. A choice between biological, mechanical prosthesis, or valve repair was done preoperatively according to the age of the patients, the patient's preference, and their compliance with long-term anticoagulation, as well as the intraoperative findings and the degree of macroscopic valve destruction. The affected areas underwent extensive debridement with copious irrigation. The defected areas were repaired either through isolated valve replacement or aortic root reconstruction with or without autologous or 
bovine pericardium in cases of extensive destruction or the presence of an abscess. Continuous $\mathrm{CO}_{2}$ insufflation was used as a standard for cardiac de-airing. Transesophageal echocardiography is used for assessment after surgical repair and to control the presence of residual air in the left side of the heart during rewarming.

\subsection{Statistical Analysis}

Statistical analysis was performed using the SPSS Statistics software (Version 24.0, Chicago, IL, USA). The normality of continuous variables was assessed by the KolmogorovSmirnov-Test. Normally distributed data are presented as the mean \pm standard deviation and not normally distributed data as median with range or interquartile range as appropriate. Categorical variables are displayed as frequency distributions (n) and simple percentages (\%). Univariate comparison between the groups for categorical variables was made using the $x^{2}$ and the Fisher's exact test as appropriate, while quantitative variables were compared by the $t$-test or Mann-Whitney-U-Test if they were not normally distributed. Statistical significance was considered when $p \leq 0.05$. Variables associated with 30 -day mortality were selected due to clinical relevance and included in multivariable logistic regression analysis with backward elimination to determine their relative impact (adjusted odds ratio, OR) on 30-day mortality. Included variables were age, Euro-SCORE II, female gender, coronary heart disease, poor LVEF, presence of previous cardiac surgery, cardiogenic shock, preoperative hemodialysis, preoperative stroke, and presence of an abscess.

\section{Results}

Analysis of the demographic and preoperative status showed that INVE present in 242 patients (59\%) without history of previous cardiac surgery while 171 patients $(41 \%)$ underwent surgery due to IPVE. Patient with IPVE were significantly older than patients with INVE $(64.9 \pm 13.2$ years vs. $58.3 \pm 15.5$ years; $p<0.001)$ with higher percentage of patients older than 70 years $(77(45.0 \%)$ years vs. $60(24.8 \%)$ years; $p<0.001))$. EuroSCORE II was significantly higher among IPVE group $(21.2(12.7 ; 41.8)$ vs. $6.9(3.0 ; 17.0) ; p<0.001))$. Those patients suffered more significantly from coronary heart disease $(50.6 \%$ vs. $38.0 \%$; $p<0.011)$, poorer LVEF under $30 \%(24(14.9 \%)$ vs. $17(7.4 \%)$ years; $p=0.017))$ and arterial hypertension (1 $29(75.4 \%)$ vs. $111(45.9 \%) ; p<0.001)$. The incidence of infective endocarditis that required surgical intervention increased yearly. Figure 1 represents the course of IE over the last 18 years.

\section{IE-Incidence/Year}

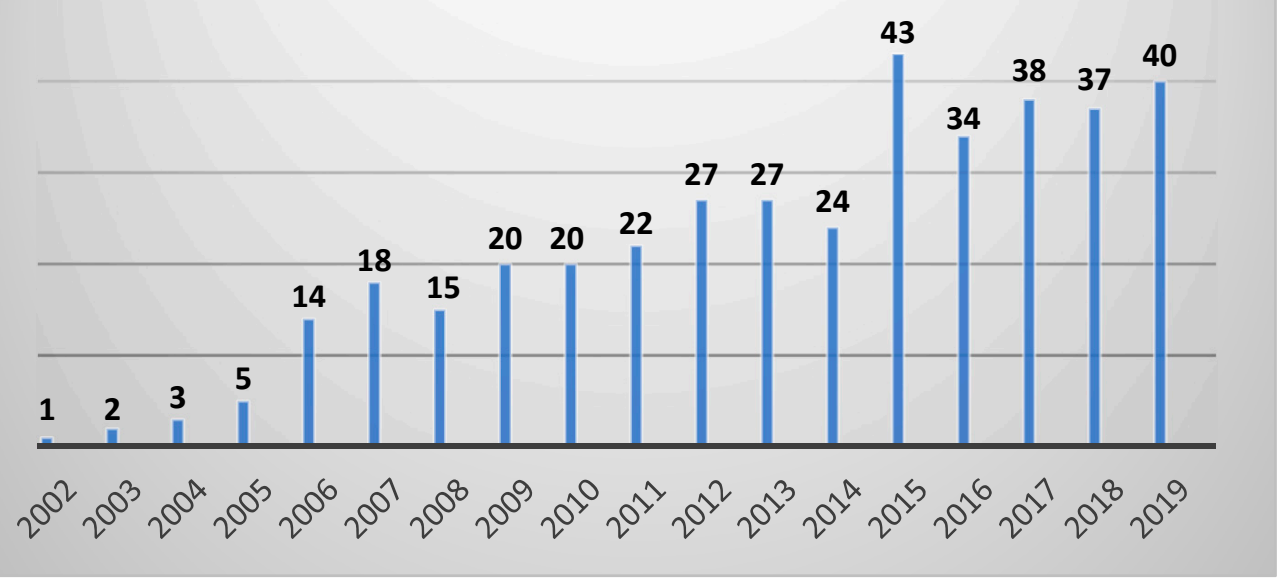

Figure 1. Showing the yearly incidence of infective endocarditis treated surgically over the last 18 years. 
Intravenous drug abuse was noticed in 23 patients (5.6\% of the study population). It was more common in patient with INVE $(18(7.4 \%)$ vs. $5(2.9 \%) ; p=0.049)$. Preoperative embolization was significantly higher among those patients with INVE ( $35.5 \%$ vs. $16.4 \%$; $p<0.001)$. Cerebral embolization was with the highest incidence and represent 58 patients $(14 \%)$ of the total $(18.6 \%$ in INVE vs. $7.6 \%$ in IPVE; $p=0.001)$. Spleen embolization was the second most common embolization with 17 patients (4.1\%). On the other side, patients with IPVE were significantly represented with intracardiac abscess $(44.4 \%$ vs. $15.7 \% ; p<0.001)$. A history of recurrent endocarditis reaches $14.5 \%$ of the total population with a significantly higher incidence in patients with IPVE $(43(25.1 \%)$ vs. $17(7.0 \%) ; p<0.001)$. Among the total study population, $21.8 \%$ underwent emergency surgery, in which patients with INVE significantly required an emergency intervention than those with IPVE ( $29.8 \%$ vs. $10.5 \%$; $p<0.001$.

Among those patients with IPVE, 96 patients (56.1\%) represented with a previous history of combined valve surgery, 69 patients $(40.4 \%)$ with isolated aortic valve replacement, 6 patients (3.5\%) with isolated mitral valve replacement/resection 2 patients $(1.2 \%)$ with transcatheter aortic valve implantation (TAVI).

The aortic valve was the most commonly affected valve with regurgitation of at least grade II $(108 ; 26.3 \%)$ followed by mitral valve $78(19.0 \%)$ and tricuspid valve $8(1.9 \%)$.

There were 134 patients $(33.1 \%$ ) found with vegetation measuring $11-20 \mathrm{~mm}$, followed by 63 patients $(15.6 \%)$ with $5-10 \mathrm{~mm}$; and 49 patients $(12.1 \%)$ were found with vegetation that measured less than $5 \mathrm{~mm}$. In general, large vegetation that measured 11-20 $\mathrm{mm}$ was commonly found on native valves than prosthetic valves $(95(40.6 \%)$ vs.39 $(22.8 \%) ;<0.001)$. Data of microbiological analysis showed a high incidence of infection with Staphylococcus aureus in 82 patients $(20.0 \%)$, followed by Enterococcus in 61 patients $(14.8 \%)$, then Streptococcus viridans in 43 patients (10.5\%). In 113 patients (27.5\%) there was no evidence of microorganisms (62 patients (25.7\%) in INVE and 51 patients (30.0\%) in IPVE). See Table 1.

Table 1. Demographic and clinical characteristics of the study population.

\begin{tabular}{|c|c|c|c|c|}
\hline & All Patients $(n=413)$ & INVE $(n=242,59 \%)$ & IPVE $(n=171,41 \%)$ & $p$-Value \\
\hline Age, years & $\begin{array}{l}61.1 \pm 14.9 \\
64(52 ; 73)\end{array}$ & $\begin{array}{l}58.3 \pm 15.5 \\
62(48 ; 69)\end{array}$ & $\begin{array}{l}64.9 \pm 13.2 \\
68(56 ; 75)\end{array}$ & $<0.001$ \\
\hline Female gender & $105(25.4 \%)$ & $59(24.4 \%)$ & $46(26.9 \%)$ & 0.562 \\
\hline EuroSCORE II & $12.1(5.2 ; 27.3)$ & $6.9(3.0 ; 17.0)$ & $21.2(12.7 ; 41.8)$ & $<0.001$ \\
\hline Chronic obstructive lung disease (COPD) & $50(12.1 \%)$ & $24(9.9 \%)$ & $26(15.2 \%)$ & 0.105 \\
\hline Arterial hypertension & $240(58.1 \%)$ & $111(45.9 \%)$ & $129(75.4 \%)$ & $<0.001$ \\
\hline Left ventricle ejection fraction (LVEF ) (\%) & $55(49 ; 55)$ & $55(50 ; 55)$ & $55(45 ; 55)$ & 0.128 \\
\hline Drug abuse & $23(5.6 \%)$ & $18(7.4 \%)$ & $5(2.9 \%)$ & 0.049 \\
\hline Acute dialysis preoperative & $27(6.5 \%)$ & $18(7.4 \%)$ & $9(5.3 \%)$ & 0.378 \\
\hline Chronic dialysis preoperative & $18(4.4 \%)$ & $10(4.1 \%)$ & $8(4.7 \%)$ & 0.789 \\
\hline NYHA IV & $83(20.2 \%)$ & $56(23.3 \%)$ & $27(15.9 \%)$ & 0.064 \\
\hline Coronary heart disease & $178(43.2 \%)$ & $92(38.0 \%)$ & $86(50.6 \%)$ & 0.011 \\
\hline Previous aortic valve replacement & $69(16.7 \%)$ & $0(0 \%)$ & $69(40.4 \%)$ & $<0.001$ \\
\hline $\begin{array}{l}\text { Previous mitral valve } \\
\text { replacement/resection }\end{array}$ & $6(1.5 \%)$ & $0(0 \%)$ & $6(3.5 \%)$ & $<0.001$ \\
\hline Combined valve surgery & $79(19.1 \%)$ & $0(0 \%)$ & $96(56.1 \%)$ & $<0.001$ \\
\hline
\end{tabular}


Table 1. Cont.

\begin{tabular}{|c|c|c|c|c|}
\hline & All Patients $(n=413)$ & INVE $(n=242,59 \%)$ & IPVE $(n=171,41 \%)$ & $p$-Value \\
\hline $\begin{array}{l}\text { Previous transcatheter aortic valve } \\
\text { implantation (TAVI) }\end{array}$ & $2(0.5 \%)$ & $0(0 \%)$ & $2(1.2 \%)$ & $<0.001$ \\
\hline Emergency & $90(21.8 \%)$ & $72(29.8 \%)$ & $18(10.5 \%)$ & $<0.001$ \\
\hline Neurological deficits & $81(19.6 \%)$ & $60(24.8 \%)$ & $21(12.3 \%)$ & 0.002 \\
\hline Pre-OP embolization & $114(27.6 \%)$ & $86(35.5 \%)$ & $28(16.4 \%)$ & $<0.001$ \\
\hline cerebral embolization & $58(14.0 \%)$ & $45(18.6 \%)$ & $13(7.6 \%)$ & 0.001 \\
\hline spleen & $17(4.1 \%)$ & $13(5.4 \%)$ & $4(2.3 \%)$ & 0.001 \\
\hline other organs & $11(2.7 \%)$ & $8(3.3 \%)$ & $3(1.8 \%)$ & 0.001 \\
\hline several organs & $28(6.8 \%)$ & $20(8.3 \%)$ & $8(4.7 \%)$ & 0.001 \\
\hline \multicolumn{5}{|l|}{ Pathogens } \\
\hline Staphylococcus aureus & $82(20.0 \%)$ & $54(22.4 \%)$ & $28(16.5 \%)$ & \\
\hline Enterococcus & $61(14.8 \%)$ & $28(11.6 \%)$ & $33(19.4 \%)$ & \\
\hline Viridans streptococci & $43(10.5 \%)$ & $40(16.6 \%)$ & $3(1.8 \%)$ & \\
\hline Gram-positive streptococcus & $37(9.0 \%)$ & $23(9.5 \%)$ & $14(8.2 \%)$ & \\
\hline Systemic mycoses & $6(1.5 \%)$ & $2(0.8 \%)$ & $4(2.4 \%)$ & \\
\hline Staphylococcus epidermis & $28(6.8 \%)$ & $12(5.0 \%)$ & $16(9.4 \%)$ & \\
\hline other & $39(9.5 \%)$ & $19(7.9 \%)$ & $20(11.8 \%)$ & \\
\hline non-pathogen & $113(27.5 \%)$ & $62(25.7 \%)$ & $51(30.0 \%)$ & \\
\hline MRSA & $14(3.4 \%)$ & $10(4.1 \%)$ & $4(2.4 \%)$ & 0.326 \\
\hline \multicolumn{5}{|l|}{ Common Affected Valve } \\
\hline Aortic valve endocarditis & $128(31.0 \%)$ & $122(50.4 \%)$ & $0(0 \%)$ & \\
\hline Mitral valve endocarditis & $92(22.3 \%)$ & $74(30.6 \%)$ & $0(0 \%)$ & \\
\hline Tricuspid valve endocarditis & $7(1.7 \%)$ & $5(2.1 \%)$ & $0(0 \%)$ & \\
\hline Prosthetic valve endocarditis & $171(41.4 \%)$ & $0(0.0 \%)$ & $171(100 \%)$ & \\
\hline \multicolumn{5}{|l|}{ Common valve insufficiency (at least grade 2) } \\
\hline Aortic valve & $108(26.3 \%)$ & $103(42.9 \%)$ & $5(2.9 \%)$ & \\
\hline Mitral valve & $78(19.0 \%)$ & $67(27.9 \%)$ & $11(6.4 \%)$ & \\
\hline Tricuspid valve & $8(1.9 \%)$ & $6(2.5 \%)$ & $2(1.2 \%)$ & \\
\hline Peri-annular Abscess & $113(27.8 \%)$ & $37(15.7 \%)$ & $76(44.4 \%)$ & $<0.001$ \\
\hline Vegetation & $285(70.4 \%)$ & $184(78.6 \%)$ & $101(59.1 \%)$ & \\
\hline$<5 \mathrm{~mm}$ & $49(12.1 \%)$ & $29(12.4 \%)$ & $20(11.7 \%)$ & \\
\hline $5-10 \mathrm{~mm}$ & $63(15.6 \%)$ & $33(14.1 \%)$ & $30(17.5 \%)$ & $<0.001$ \\
\hline $11-20 \mathrm{~mm}$ & $134(33.1 \%)$ & $95(40.6 \%)$ & $39(22.8 \%)$ & \\
\hline$>20 \mathrm{~mm}$ & $39(9.6 \%)$ & $27(11.5 \%)$ & $12(7.0 \%)$ & \\
\hline
\end{tabular}

Intraoperatively, the length of surgery was as expected significantly higher in the IPVE group $(356(299 ; 428) \mathrm{min}$. vs. $244(198 ; 281) \mathrm{min}$.; $p=0.001)$ as well as cardiopulmonary bypass time $(208(169 ; 259) \mathrm{min}$. vs. $144(111 ; 177) \mathrm{min} . ; p<0.001)$ and transfusion of blood conserves $(4(0-27)$ vs. $2(0-14) ; p<0.001)$. Aortic valves were replaced in 305 patients $(74.2 \%)$, in which 190 patients $(46.2 \%)$ of them underwent valve replacement with a bioprosthetic valve and 27 patients (6.6\%) underwent a mechanical valve replacement. Mitral valve surgery was carried out in 155 patients; 111 patients $(27.0 \%)$ underwent bioprosthetic valve replacement, $13(3.2 \%)$ patients underwent a mechanical valve replacement, and 31 patients $(7.5 \%)$ underwent mitral valve repair with bioprosthetic annuloplasty. See Table 2.

Post-operatively, the incidence of bleeding was markedly higher in the IPVE group $((700 \mathrm{~mL}(438 ; 1163)$ vs. $500 \mathrm{~mL}(250 ; 1075) ; p=0.005)$. Blood transfusion was markedly significant in IPVE (4 units $(0-27)$ vs. 2 units $(0-14) ; p<0.001)$. Patients in the IPVE group suffered from atrioventricular bradyarrhythmia required significantly more pacemaker (17.6\% vs. $7.5 \%: p=0.002$ ). The 30 -day mortality was $17.9 \%$ (74 patients). Patients who suffered from a new onset of stroke represent $4.5 \%$ (18 patients) of the whole population without significant difference in both patients with INVE or IPVE. The 30-day mortality was 
$17.9 \%$ (74 patients). The mortality rate was also higher in the IPVE group ( $24.6 \%$ vs. $13.2 \%$; $p<0.003)$, Table 3.

Table 2. Operative data.

\begin{tabular}{|c|c|c|c|c|}
\hline & All Patients $(n=413)$ & INVE $(n=242,59 \%)$ & IPVE $(n=171,41 \%)$ & $p$-Value \\
\hline Length of surgery (min) & $273(220 ; 355)$ & $244(198 ; 281)$ & $356(299 ; 428)$ & $<0.001$ \\
\hline Cardiopulmonary bypass time (min) & $166(125 ; 215)$ & $144(111 ; 177)$ & $208(169 ; 259)$ & $<0.001$ \\
\hline Cross-clamp time (min) & $116(86 ; 156)$ & $99(77 ; 124)$ & $154(117 ; 181)$ & $<0.001$ \\
\hline Circulatory arrest (min) & $0(0-36)$ & $0(0-32)$ & $0(0-36)$ & $<0.001$ \\
\hline Number of packed red blood cells, unit & $3(0-27)$ & $2(0-14)$ & $4(0-27)$ & $<0.001$ \\
\hline Number of fresh frozen plasma, unit & $0(0-13)$ & $0(0-8)$ & $0(0-13)$ & $<0.001$ \\
\hline Number of platelets, unit & $1(0-6)$ & $1(0-6)$ & $1(0-6)$ & $<0.001$ \\
\hline Aortic valve surgery: & $305(74.2 \%)$ & $162(66.9 \%)$ & $143(84.6 \%)$ & $<0.001$ \\
\hline Biological replacement & $190(46.2 \%)$ & $124(51.2 \%)$ & $66(39.1 \%)$ & $<0.001$ \\
\hline Mechanical replacement & $27(6.6 \%)$ & $20(8.3 \%)$ & $7(4.1 \%)$ & $<0.001$ \\
\hline Aortic root replacement & $80(19.5 \%)$ & $15(6.2 \%)$ & $65(38.5 \%)$ & $<0.001$ \\
\hline Mitral valve surgery: & $155(37.7 \%)$ & $114(47.1 \%)$ & $41(24.3 \%)$ & $<0.001$ \\
\hline Biological replacement & $111(27.0 \%)$ & $78(32.2 \%)$ & $33(19.5 \%)$ & $<0.001$ \\
\hline Mechanical replacement & $13(3.2 \%)$ & $12(5.0 \%)$ & $1(0.6 \%)$ & $<0.001$ \\
\hline Repair surgery & $31(7.5 \%)$ & $24(9.9 \%)$ & $7(4.1 \%)$ & $<0.001$ \\
\hline Tricuspid valve surgery & $15(3.6 \%)$ & $13(5.4 \%)$ & $2(1.2 \%)$ & 0.026 \\
\hline Biological replacement & $3(0.7 \%)$ & $2(0.8 \%)$ & $1(0.6 \%)$ & 0.033 \\
\hline Repair surgery & $12(2.9 \%)$ & $11(4.5 \%)$ & $1(0.6 \%)$ & 0.033 \\
\hline
\end{tabular}

Table 3. Post-operative data and outcomes.

\begin{tabular}{|c|c|c|c|c|}
\hline & All Patients $(n=413)$ & $\begin{array}{c}\text { INVE } \\
(n=242,59 \%)\end{array}$ & $\begin{array}{c}\text { IPVE } \\
(n=171,41 \%)\end{array}$ & $p$-Value \\
\hline AKI KDIGO & $115(29.3 \%)$ & $59(25.1 \%)$ & $56(35.4 \%)$ & 0.027 \\
\hline New-onset of Hemodialysis & $61(15.6 \%)$ & $31(13.2 \%)$ & $30(19.0 \%)$ & 0.124 \\
\hline Hemodialysis, days & $5(3 ; 9)$ & $5(3 ; 8)$ & $4(2 ; 13)$ & 0.527 \\
\hline 24 h-drainage loss (mL) & $600(300 ; 1100)$ & $500(250 ; 1075)$ & $700(438 ; 1163)$ & 0.005 \\
\hline Rethoracotomy due to bleeding/tamponade & $50(12.4 \%)$ & $30(12.6 \%)$ & $20(12.1 \%)$ & 0.897 \\
\hline 24 h-Number of packed red blood cells, unit, & $2(0-27)$ & $2(0-21)$ & $2(0-27)$ & 0.334 \\
\hline 24 h-Number of fresh frozen plasma, unit, & $0(0-29)$ & $0(0-18)$ & $3(0-29)$ & $<0.001$ \\
\hline 24 h-Number of platelets, unit, & $0(0-8)$ & $0(0-5)$ & $0(0-8)$ & 0.359 \\
\hline 48 h-number of packed red blood cells, unit, & $2(0-27)$ & $2(0-23)$ & $2(0-27)$ & 0.401 \\
\hline 48 h-number of fresh frozen plasma, unit, & $0(0-35)$ & $0(0-24)$ & $3(0-35)$ & 0.001 \\
\hline 48 h-number of platelets, unit, & $0(0-9)$ & $0(0-6)$ & $0(0-9)$ & 0.673 \\
\hline Ventilation time $(\mathrm{h})$ & $16(9 ; 45)$ & $15(9 ; 46)$ & $17(10 ; 44)$ & 0.323 \\
\hline Reintubation & $49(12.3 \%)$ & $29(12.1 \%)$ & $20(12.5 \%)$ & 0.901 \\
\hline Tracheotomy & $57(14.5 \%)$ & $32(13.7 \%)$ & $25(15.8 \%)$ & 0.554 \\
\hline Intensive care unit stay $(\mathrm{d})$ & $3(1 ; 7)$ & $3(1 ; 7)$ & $3(1 ; 8)$ & 0.381 \\
\hline Post-operative delirium & $64(16.1 \%)$ & $33(13.8 \%)$ & $31(19.7 \%)$ & 0.112 \\
\hline Neurologic damage & $27(6.8 \%)$ & $15(6.3 \%)$ & $12(7.6 \%)$ & 0.617 \\
\hline
\end{tabular}


Table 3. Cont.

\begin{tabular}{|c|c|c|c|c|}
\hline & All Patients $(n=413)$ & $\begin{array}{c}\text { INVE } \\
(n=242,59 \%)\end{array}$ & $\begin{array}{c}\text { IPVE } \\
(n=171,41 \%)\end{array}$ & $p$-Value \\
\hline Cardiopulmonary resuscitation & $22(5.5 \%)$ & $12(5.0 \%)$ & $10(6.3 \%)$ & 0.591 \\
\hline Pacemaker patient & $47(11.6 \%)$ & $18(7.5 \%)$ & $29(17.6 \%)$ & 0.002 \\
\hline Post-operative myocardial infarction & $5(1.3 \%)$ & $4(1.7 \%)$ & $1(0.6 \%)$ & 0.652 \\
\hline Bronchopulmonary infection & $45(11.1 \%)$ & $25(10.4 \%)$ & $20(12.0 \%)$ & 0.607 \\
\hline Sepsis & $54(13.3 \%)$ & $28(11.7 \%)$ & $26(15.6 \%)$ & 0.254 \\
\hline Sternal wound infection & $9(2.5 \%)$ & $7(3.1 \%)$ & $2(1.4 \%)$ & 0.492 \\
\hline 30 d-Mortality & $74(17.9 \%)$ & $32(13.2 \%)$ & $42(24.6 \%)$ & 0.003 \\
\hline \multicolumn{5}{|l|}{ Common causes of death } \\
\hline Cardiac death & $10(14.3 \%)$ & $2(6.9 \%)$ & $8(19.5 \%)$ & 0.247 \\
\hline Cerebral death & $1(1.4 \%)$ & $0(0 \%)$ & $1(2.4 \%)$ & 0.247 \\
\hline Sepsis & $9(12.9 \%)$ & $3(10.3 \%)$ & $6(14.6 \%)$ & 0.247 \\
\hline Survival/follow-up time (years) & $3.1(0.4 ; 7.1)$ & $3.8(0.9 ; 8.2)$ & $1.8(0.1 ; 5.3)$ & $<0.001$ \\
\hline
\end{tabular}

AKI: Acute kidney injury; KDIGO: Kidney Disease Improving Global Outcomes.

The mean follow-up was 3.1 years $(0.4 ; 7.1)$. Figure 1 shows the survival curves estimated by the Kaplan-Meier method. One-year (65\% vs. $79 \%$ ), 3 -years (58\% vs. $71 \%$ ) and 5 -years (51\% vs. $66 \%$ ) survival rates were significantly lower in the IPVE group $(p<0.001)$.

A multivariate logistic regression analysis for 30-day mortality in endocarditis patients showed that patients with acute or chronic dialysis (odds ratio (OR) 2.754; $p=0.012$ ), NYHA IV (OR 3.055; $p=0.001)$, neurological deficits (OR 2.976; $p=0.002$ ) and abscess (OR 2.306; $p=0.010)$ were independent risk factors for mortality. Table 4 .

Table 4. Logistic regression analysis for 30-day mortality in endocarditis patients.

\begin{tabular}{cccc}
\hline Predictors & Odds Ratio & $\mathbf{9 5 \%}$ CI & $p$-Value \\
\hline Female gender & 2.076 & $1.095-3.934$ & 0.025 \\
\hline Age (years) & 1.028 & $1.004-1.053$ & 0.021 \\
\hline Dialysis (acute and chronic) & 2.754 & $1.247-6.080$ & 0.012 \\
\hline NYHA 4 & 3.055 & $1.544-6.044$ & 0.001 \\
\hline Prosthetic valve endocarditis & 2.162 & $1.085-4.311$ & 0.028 \\
\hline Cardiogenic shock & 3.946 & $1.199-12.990$ & 0.024 \\
\hline Neurological deficits (TIA or stroke) & 2.976 & $1.481-5.981$ & 0.002 \\
\hline Abscess & 2.306 & $1.220-4.361$ & 0.010 \\
\hline
\end{tabular}

CI: Confidence interval; TIA: Transient ischemic attack.

\section{Discussion}

Despite of the huge evolution of both the role of antibiotics therapy to control and prevent the septic condition, as well as in the diagnostic and intervention tools, infective endocarditis is still considered a disease with significant morbidity and mortality $[1,6,8]$. The course of IE is unpredictable and in severe cases, it is difficult to be controlled, associated with a poor prognosis. Congestive heart failure followed by acute stroke is considered the most common complication of left-sided infective endocarditis, in addition to valvular incompetence.

Our analysis showed that the left-sided heart valves were commonly involved than the right ones. The aortic valve involvement comes in the first line followed by the mitral valve. Our findings went in line with several studies [8-11], where others found that the mitral 
valve was the most frequently affected [2,12]. IE of the right-side native valves represents $<5 \%$ of all cases and it is known to be a common complication in patients with intravenous drug abusers or patients with pacemakers with intracardiac leads or those with prolonged central venous lines [13]. Isolated prosthetic endocarditis after valve surgery represents $34.6 \%$ of the study population. IPVE is associated with a high incidence of intracardiac abscess formation. Moreover, it is characterized by high recurrent rates reaching up to $15 \%$, and poorer prognosis than in native valve IE [14,15]. Large vegetation measured more than $11 \mathrm{~mm}$ was found more commonly on native valves than prosthetic valves.

Microbiological analysis showed a high incidence of infection with Staphylococcus aureus followed by Enterococcus and Streptococcus viridans. A study by Fowler et al. found that infection with Staphylococcus aureus is considered an independent predictor of mortality and associated with large vegetation, high incidence of paravalvular abscesses, and low survival rate [16]. In about $27.5 \%$ of the study population, there was no evidence of microorganisms. Lamas et al. stated that up to $31 \%$ of cases with IE often represented with negative blood culture [17]. This may be contributing to the early administration of broad-spectrum antibiotics regimes before blood culture. Murdoch et al. found in his analysis that infection with Streptococcus viridans was associated with a decreased risk of in-hospital mortality [2].

Our results found that $18.4 \%$ suffered from preoperative stroke with a high incidence among INVE rather than IPVE. In the post-operative analysis, the new onset of stroke was relatively low $(4.5 \%)$ without significant difference in both patients with INVE or IPVE. This also contributes to the early administration of antibiotics. Dickerman et al. proved the efficiency of antimicrobial therapy in a reduction in stroke rate [18]. Other studies reported an incidence of a manifested ischemic stroke reaching up to $20-35 \%$, as well as a non-manifested neurological event reaching up to $50 \%$ [19].

In the current analysis, $21.8 \%$ of the total population underwent emergency surgery. The level of emergency depends on various factors such as hemodynamic state, degree of the septic condition, and the risk of cerebral embolism. The incidence of emergency surgery was significantly higher in patients with INVE than patients with IPVE (29.8\% vs. $10.5 \%$; $p<0.001)$. The main focus of emergency surgery is for curative aims to prevent recurrent stroke and to restore the valvular function to avoid the rapid deterioration of congestive heart failure [2].

However, the ideal timing for surgical intervention in IE remains controversial. We found that the postponement of surgical therapy in patients diagnosed with IE until an occurrence of silent events-according to the guidelines and recommendation of the European Society of Cardiology (ESC) [19]—represents a point of debate. Silent events might not be well recognized or they could be interpreted otherwise. The patients might progress directly to a manifested irreversible ischemic event. Adding to that a delay to removal of intracardiac vegetation or abscess might markedly deteriorate the hemodynamic, progress to valvular and para-valvular destruction as well as the course of sepsis might be out of control regardless of the antimicrobial therapy. Various studies-in line with our study-recommend an early surgical intervention as soon as possible, regardless of stroke manifestation. A marked hemodynamic deterioration was reported due to surgical delay (after 1-2 weeks) more than the expected hazards of carrying out surgery under cardiopulmonary bypass [20,21].

The 30-day mortality rate in the current analysis reaches $17.9 \%$, which is near to the known mortality rate of between $8-25 \%$ according to the recent ESC guidelines and other studies $[6,8,10]$. The risk factors for mortality were multifactorial. Our regression analysis showed that patients who required dialysis, either acute or chronic, as well as patients represented with neurological deficits and suffered from an intracardiac abscess, or those with prosthetic valve endocarditis are considered independent factors for mortality. Patients with IPVE had a significantly higher mortality rate $(24.6 \%)$ when compared to INVE (13.2\%). The long-term survival showed as well an acceptable result for INVE in comparison to IPVE. Our findings were confirmed by various studies regarding the risk factors of mortality and long-term survival $[8,11,22]$. However, other studies showed 
no significant differences regarding the long-term survival between both groups [10]. Moreover, various studies proved that infectious organisms could influence post-operative survival, where infections with Staphylococcus aureus were significantly associated with post-operative mortality when compared with non-S. aureus IE [8]. David TE et al. proved in an analysis that prosthetic valve endocarditis, as well as impaired ventricular function, adversely affects long-term survival, as mentioned in our study [22].

\section{Conclusions}

Patients with INVE were represented with a high incidence of preoperative embolization and neurological deficits. The aortic valve is commonly affected and patients underwent surgery frequently on an emergency basis. However, the survival rate is acceptable. Patients with IPVE were represented commonly with intracardiac abscess and characterized by high incidence of recurrence. Those patients had a higher incidence of pacemaker implantation. The mortality rate among those patients was still high.

Author Contributions: Conceptualization, all authors; methodology, M.S. (Mohamed Salem) and A.H.; software, C.F.; validation, M.S. (Mohamed Salem), F.S., J.S., J.C. and A.H.; formal analysis, M.S. (Mohamed Salem) and C.F.; investigation, M.S. (Mohamed Salem), M.S. (Mostafa Salem) and A.H.; resources, M.S. (Mostafa Salem), M.S. (Mohamed Salem) and A.H.; data curation, all authors; writing—original draft preparation, M.S. (Mohamed Salem); writing—review and editing, all authors; visualization, all authors; supervision, D.F., M.S. (Mohammed Saad), A.H. and J.C.; project administration, M.S. (Mohamed Salem) and A.H.; funding acquisition, none. All authors have read and agreed to the published version of the manuscript.

Funding: This research received no external funding.

Institutional Review Board Statement: The study was conducted according to the guidelines of the Declaration of Helsinki, and approved by the Ethics Committee of Christian-Albrecht-University (protocol code D 458/20).

Informed Consent Statement: Informed consent was obtained from all subjects involved in the study.

Data Availability Statement: Data is available upon requirement.

Conflicts of Interest: The authors declare no conflict of interest.

\section{References}

1. Habib, G.; Erba, P.A.; Iung, B.; Donal, E.; Cosyns, B.; Laroche, C.; Popescu, B.A.; Prendergast, B.; Tornos, P.; Sadeghpour, A.; et al. Clinical presentation, aetiology and outcome of infective endocarditis. Results of the ESC-EORP EURO-ENDO (European infective endocarditis) registry: A prospective cohort study. Eur. Heart J. 2019, 40, 3222-3232. [CrossRef] [PubMed]

2. Murdoch, D.R.; Corey, G.R.; Hoen, B.; Miró, J.M.; Fowler, V.G., Jr.; Bayer, A.S.; Karchmer, A.W.; Olaison, L.; Pappas, P.A.; Moreillon, P.; et al. Clinical presentation, etiology, and outcome of infective endocarditis in the 21st century: The International Collaboration on Endocarditis-Prospective Cohort Study. Arch. Intern. Med. 2009, 169, 463-473. [CrossRef] [PubMed]

3. Olaison, L.; Pettersson, G. Current best practices and guidelines indications for surgical intervention in infective endocarditis. Infect. Dis. Clin. N. Am. 2002, 16, 453-475. [CrossRef]

4. Daniel, W.G.; Mügge, A.; Martin, R.P.; Lindert, O.; Hausmann, D.; Nonnast-Daniel, B.; Laas, J.; Lichtlen, P.R. Improvement in the diagnosis of abscesses associated with endocarditis by transesophageal echocardiography. N. Engl. J. Med. 1991, 324, 795-800. [CrossRef]

5. Bonow, R.O.; Carabello, B.A.; Kanu, C.; De Leon, A.C., Jr.; Faxon, D.P.; Freed, M.D.; Gaasch, W.H.; Lytle, B.W.; Nishimura, R.A.; O'Gara, P.T.; et al. ACC/AHA 2006 guidelines for the management of patients with valvular heart disease: A report of the American College of Cardiology / American Heart Association Task Force on Practice Guidelines (Writing Committee to Revise the 1998 Guidelines for the Management of Patients with Valvular Heart Disease). Circulation 2006, 114, e84-e231. [PubMed]

6. Luciani, N.; Mossuto, E.; Ricci, D.; Luciani, M.; Russo, M.; Salsano, A.; Pozzoli, A.; Pierri, M.D.; D'Onofrio, A.; Chiariello, G.A.; et al. Prosthetic valve endocarditis: Predictors of early outcome of surgical therapy. A multicentric study. Eur. J. Cardiothorac. Surg. 2017, 52, 768-774. [CrossRef]

7. Edlin, P.; Westling, K.; Sartipy, U. Long-term survival after operations for native and prosthetic valve endocarditis. Ann. Thorac. Surg. 2013, 95, 1551-1556. [CrossRef]

8. Manne, M.B.; Shrestha, N.K.; Lytle, B.W.; Nowicki, E.R.; Blackstone, E.; Gordon, S.M.; Pettersson, G.; Fraser, T.G. Outcomes after surgical treatment of native and prosthetic valve infective endocarditis. Ann. Thorac. Surg. 2012, 93, 489-493. [CrossRef] 
9. Plicht, B.; Lind, A.; Erbel, R. InfektiöseEndokarditis: Neue Leitlinien 2015 [Infective endocarditis: New ESC guidelines 2015]. Internist 2016, 57, 675-690. [CrossRef] [PubMed]

10. Kaiser, S.P.; Melby, S.J.; Zierer, A.; Schuessler, R.B.; Moon, M.R.; Moazami, N.; Pasque, M.K.; Huddleston, C.; Damiano, R.J., Jr.; Lawton, J.S. Long-term outcomes in valve replacement surgery for infective endocarditis. Ann. Thorac. Surg. 2007, 83, 30-35. [CrossRef]

11. David, T.E.; Gavra, G.; Feindel, C.M.; Regesta, T.; Armstrong, S.; Maganti, M.D. Surgical treatment of active infective endocarditis: A continued challenge. J. Thorac. Cardiovasc. Surg. 2007, 133, 144-149. [CrossRef]

12. Pang, P.Y.K.; Sin, Y.K.; Lim, C.H.; Tan, T.E.; Lim, S.L.; Chao, V.T.; Chua, Y.L. Surgical management of infective endocarditis: An analysis of early and late outcomes. Eur. J. Cardiothorac. Surg. 2015, 47, 826-832. [CrossRef]

13. Miro, J.M.; del Rio, A.; Mestres, C.A. Infective endocarditis and cardiac surgery in intravenous drug abusers and HIV-1 infected patients. Cardiol. Clin. 2003, 21, 167-184. [CrossRef]

14. Lytle, B.W.; Priest, B.P.; Taylor, P.C.; Loop, F.D.; Sapp, S.K.; Stewart, R.W.; McCarthy, P.M.; Muehrcke, D.; Cosgrove, D.M. Surgical treatment of prosthetic valve endocarditis. J. Thorac. Cardiovasc. Surg. 1996, 111, 198-207. [CrossRef]

15. Wang, A.; Athan, E.; Pappas, P.A.; Fowler, V.G., Jr.; Olaison, L.; Paré, C.; Almirante, B.; Muñoz, P.; Rizzi, M.; Naber, C. Contemporary clinical profile and outcome of prosthetic valve endocarditis. JAMA 2007, 297, 1354-1361. [CrossRef] [PubMed]

16. Fowler, V.G., Jr.; Miro, J.M.; Hoen, B.; Cabell, C.H.; Abrutyn, E.; Rubinstein, E.; Corey, G.R.; Spelman, D.; Bradley, S.F.; Barsic, B.; et al. Staphylococcus aureus endocarditis: A consequence of medical progress. JAMA 2005, 293, 3012-3021. [CrossRef]

17. Lamas, C.C.; Eykyn, S.J. Blood culture negative endocarditis: Analysis of 63 cases presenting over 25 years. Heart 2003, 89 , 258-262. [CrossRef]

18. Dickerman, S.A.; Abrutyn, E.; Barsic, B.; Bouza, E.; Cecchi, E.; Moreno, A.; Doco-Lecompte, T.; Eisen, D.P.; Fortes, C.Q.; Fowler, V.G., Jr.; et al. The relationship between the initiation of antimicrobial therapy and the incidence of stroke in infective endocarditis: An analysis from the ICE Prospective Cohort Study (ICE-PCS). Am. Heart J. 2007, 154, 1086-1094. [CrossRef] [PubMed]

19. Habib, G.; Lancellotti, P.; Antunes, M.J.; Bongiorni, M.G.; Casalta, J.P.; Del Zotti, F.; Dulgheru, R.; El Khoury, G.; Erba, P.A.; Iung, B.; et al. 2015 ESC Guidelines for the management of infective endocarditis: The Task Force for the Management of Infective Endocarditis of the European Society of Cardiology (ESC). Endorsed by: European Association for Cardio-Thoracic Surgery (EACTS), the European Association of Nuclear Medicine (EANM). Eur. Heart J. 2015, 36, 3075-3128. [CrossRef]

20. Barsic, B.; Dickerman, S.; Krajinovic, V.; Pappas, P.; Altclas, J.; Carosi, G.; Casabé, J.H.; Chu, V.H.; Delahaye, F.; Edathodu, J.; et al. International Collaboration on Endocarditis-Prospective Cohort Study Investigators. Influence of the timing of cardiac surgery on the outcome of patients with infective endocarditis and stroke. Clin. Infect. Dis. 2013, 56, 209-217. [CrossRef]

21. Ruttmann, E.; Willeit, J.; Ulmer, H.; Chevtchik, O.; Höfer, D.; Poewe, W.; Laufer, G.; Müller, L.C. Neurological outcome of septic cardioembolic stroke after infective endocarditis. Stroke 2006, 37, 2094-2099. [CrossRef] [PubMed]

22. David, T.E.; Regesta, T.; Gavra, G.; Armstrong, S.; Maganti, M.D. Surgical treatment of paravalvular abscess: Long-term results. Eur. J. Cardiothorac. Surg. 2007, 31, 43-48. [CrossRef] [PubMed] 